\title{
Double-stranded DNA antibodies: a comparison of four methods of detection
}

\author{
STANLEY D SOMERFIELD, MAURICE W ROBERTS, ROGER J BOOTH* \\ From the Department of Immunology, Auckland Hospital, and the * Department of Medicine, University of \\ Auckland School of Medicine, Auckland, New Zealand
}

SUMMARY Thirty-four antinuclear antibody (ANA) positive systemic lupus erythematosus (SLE) sera were tested for antibodies to double-stranded DNA (dsDNA) simultaneoulsy using Farr, haemagglutination, Crithidia luciliae $(\mathrm{CL})$ kinetoplast fluorescence and human metaphase chromosome fluorescence assays. Significant correlation $(p<0.05)$ was found between the Farr and CL assays, with the two fluorescence tests (CL and metaphase) displaying the greatest degree of association $(\mathrm{p}=0.00001)$. No correlation could be demonstrated between the haemagglutination test and any of the other three assays.

Six hundred and ninety-one sera from patients with a range of provisional rheumatological diagnoses were prospectively analysed for dsDNA antibodies using Farr and metaphase assays. A correlation coefficient of 0.84 was obtained between the two assays.

The metaphase assay provides comparable results to other more established assays, and because it is simple, reliable and sensitive, it should be seriously considered for routine use in testing for 8 dsDNA antibodies.

Antibodies with specificity for double-stranded DNA (dsDNA) are the hallmark of systemic lupus erythematosus (SLE). ${ }^{1} \mathrm{~A}$ number of methods are available for detecting these antibodies but they are either technically complicated or give inconsistent results between different laboratories. ${ }^{2}$ Radioimmunoassay or Farr techniques, although providing semiquantitative results with a standard deviation of about $5 \%, 3$ are laborious and time consuming. In contrast, haemagglutination assays for DNA antibodies are simple to perform and results are rapidly available, however these methods generally have poor reproducibility.

The simplest test is the immunofluorescence assay employing Crithidia luciliae (CL) as substrate ${ }^{3}$ which has demonstrated consistency when used in various laboratories $2 \mathbf{3}$ and is becoming the method of choice. ${ }^{6} 9$ We have recently described an equally simple indirect immunofluorescent method ${ }^{4}{ }^{5}$ which uses human metaphase chromosomes as a substrate. This test appears to have greater sensitivity than the Farr and CL methods without loss of specificity. ${ }^{5}$ Furthermore, because of the size and structure of human chromosomes compared to CL kinetoplasts, results with this assay are more easily read than other

Accepted for publication 18 March 1981 immunofluorescence methods.

To evaluate the feasibility of routine laboratory use of the metaphase technique we simultaneously tested 34 antinuclear antibody (ANA) positive SLE sera for the presence of antibodies to dsDNA using Farr, haemagglutination, $\mathrm{CL}$ and metaphase assays. Also we compared the results of metaphase and Farr assay on 691 ANA positive sera with a range of provisional clinical diagnoses.

\section{Material and methods}

PATIENTS AND SERA

Thirty-four consecutive sera which were ANA positive and from patients with ARA criteria SLE were examined with all four tests.

Six hundred and ninety-one ANA positive sera with a wide range of provisional clinical diagnoses were submitted for assay by both metaphase and Farr techniques. Both assays were performed without knowledge of the results of either. The correlation coefficient was determined on the results of those sera positive to either or both assays.

IMMUNOFLUORESCENT PROCEDURE Sera were examined at $1 / 8$ dilution in phosphatebuffered saline (PBS) pH 7.4. After 30 minutes 
incubation with substrate within a humid container at room temperature, slides were washed in PBS for 10 min. "Behringwerke" anti-human immunoglobulin (batch no 686D) was used as a fluorescent conjugate. Optimal dilution was 1/16. After incubation for $30 \mathrm{~min}$, slides were again washed for $10 \mathrm{~min}$, mounted in glycerol-PBS, and examined for chromosomal (metaphase assay) or kinetoplast (CL assay) fluorescence under a Leitz fluorescent microscopy using standard illumination. Sera which gave fluorescence were titred to end point.

Crithidia luciliae substrate was prepared according to the method of Aarden and colleagues ${ }^{3}$ and spotted on to wells on teflon-coated microscope slides (Pico Pac Laboratories, Box 9027, Auckland). Human metaphase chromosomes were prepared as previously described. ${ }^{4-6}$

Human peripheral blood leucocytes were stimulated with phytohaemagglutinin as described by Hungerford $^{6}$ as for human karyotype analysis. Cells were cultured for 3 days and arrested in metaphase by the addition of colchicine $20 \mu \mathrm{g} / \mathrm{ml}$ to a final concentration of $0.4 \mu \mathrm{g} / \mathrm{ml}$ in culture 2 hours prior to harvest. Cells were then spun on a Sorval GLC 1 centrifuge with multicarriers at $1000 \mathrm{rpm}$ for $8 \mathrm{~min}$. The supernatant was removed to $0.5 \mathrm{ml}$ and $4.5 \mathrm{ml}$ of $0.075 M \mathrm{KCL}$ added and mixed. After incubation for $15 \mathrm{~min}$ at room temperature $5 \mathrm{ml}$ of fresh $3 / 1$ methanol/acetic acid was added and the mixture fixed for $5 \mathrm{~min}$. After centrifugation at $1000 \mathrm{rpm}$ for $8 \mathrm{~min}$ the fixing/wash procedure was repeated twice. The cells were then concentrated and optimal cell concentration determined by arbitrary resuspension in a given volume of fixative and observing the resultant spread under phase microscopy. If cells were too concentrated they were further diluted. The resultant methanol/acetic acid fixed cell suspension was spotted, using a pasteur pipette, into wells on teflon spray-coated microscopy slides (Pico Pac Laboratories, Box 9027, Auckland) and used as substrate in the immunofluorescent assay. Up to 18 sera could be tested per slide in this way.

\section{FARR RADIOIMMUNOASSAY TEHNIQUE}

Farr radioimmunoassay was performed according to the method of Slater, Cameron and Lessof, ${ }^{8}$ using ${ }^{14} \mathrm{C}$-labelled $E$ coli dsDNA (Radiochemical Centre, Amersham, England, $<5 \%$ single stranded DNA).

\section{H A EMAGGLUTINATION}

The Fujizoki haemagglutination test kit (Fujizoki Pharmaceutical Co., Tokyo, Japan) was used for determination of all 34 ANA-positive SLE sera. The test was performed according to the manufacturer's instructions and the results assessed after two hours.
A positive test was considered to have occurred if a test serum showed haemagglutination of $1+$ or greater at a final serum dilution of $1 / 80$.

\section{Results}

After calculation of results for individual tests, positive and negative results were entered into a $2 \times 2$ contingency table (Table 1) and probabilities of association using Fisher's exact two-sided test calculated for all six combinations of the four tests taken two at a time (Table 2).

Table 1 Comparison of four assays for DNA antibody detection in 34 SLE sera

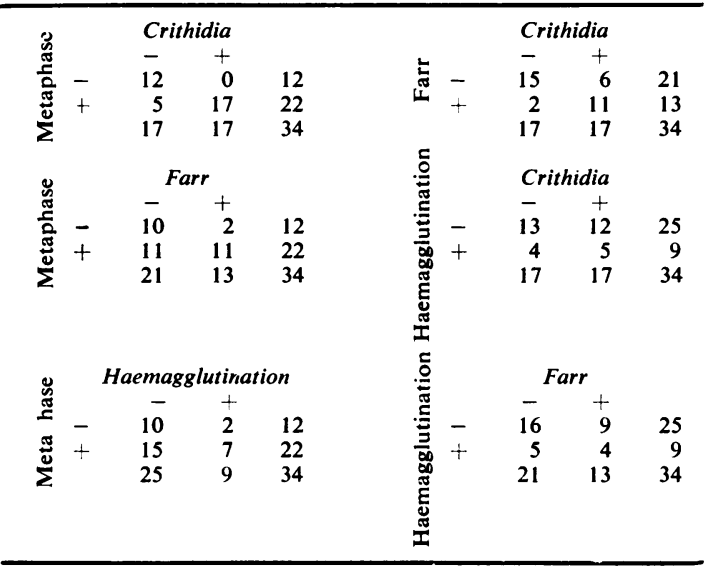

Table 2 Fisher's exact two-sided test results

\begin{tabular}{ll}
\hline Assay combination & $p$ value \\
\hline Crithidia/metaphase & $0 \cdot 00001$ \\
Crithidia/Farr & $0 \cdot 002$ \\
Metaphase/Farr & $0 \cdot 059$ \\
Farr/haemagglutination & $0 \cdot 704$ \\
Crithidia/haemagglutination & $0 \cdot 719$ \\
Metaphase/haemagglutination & $0 \cdot 297$ \\
\hline
\end{tabular}

Table 2 shows the $\mathrm{p}$ values for the six test combinations. The correlation between the results of the Farr and CL and metaphase and CL tests were highly significant, while the haemagglutination test results did not correlate well with any other test. The metaphase-Farr test combination did not quite reach statistical significance due to the metaphase assay detecting DNA antibodies in some sera which were less than $30 \%$ binding in the Farr assay.

Two sera were Farr-positive $(33 \%, 37 \%)$ but negative to all other tests. Six sera were CL-positive and Farr-negative compared with 11 metaphasepositive and Farr-negative. Although all sera which were $\mathrm{CL}$ positive were also metaphase-positive, 5 
sera were positive to metaphase, but not CL tests. These results illustrate the increased sensitivity of the metaphase method for detecting lower concentrations of dsDNA antibodies.

Of 691 sera studied prospectively for dsDNA antibodies, 114 were positive in either or both Farr and metaphase assays. The correlation coefficient between Farr and metaphase assays was 0.84 , calculated from these results, and found to be significant at the $99 \%$ level using the $\mathrm{Z}$ statistic. ${ }^{11}$ This correlation is shown in the Figure.

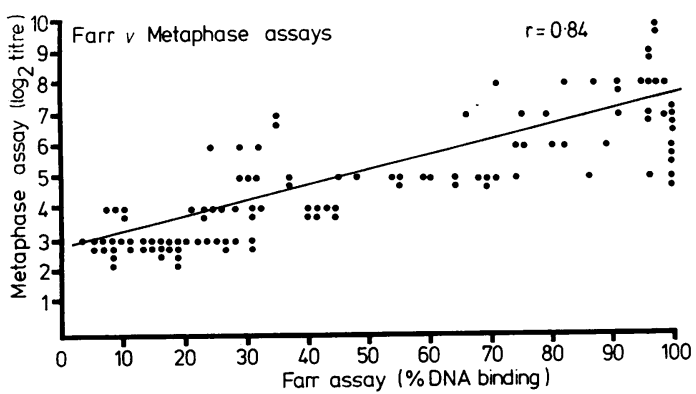

Correlation between Farr and metaphase assays on 691 sera. In metaphase assays sera were tested at $1 / 8$ or greater dilutions.

\section{Discussion}

Because of the diagnostic specificity and management implications that are attributed to the detection of antibodies to dsDNA in a given serum, ${ }^{1}$ it is important to have a sensitive and specific assay system. This must not detect antibodies to other nuclear proteins or single stranded DNA. The CL technique has been shown to be highly consistent between laboratories $^{2}$ and also to be specific for dsDNA. We report here a highly significant correlation between the $C L$ and metaphase assays $(p=0.00001)$. We have previously shown that human metaphase chromosomes can be used as an immunofluorescent substrate to detect antibodies in the sera of patients only with SLE. ${ }^{5}$ The metaphase assay, in addition, appeared to detect consistently more sera than crithidia when the two assays were compared in a preliminary study. ${ }^{4}$ This may be due to the metaphase assay being either more sensitive or alternatively detecting additional specificities compared with crithidia. Studies of the specificity of both metaphase and crithidia substrate showed that both lost reactivity with positive sera following DNAase digestion only. Furthermore the same features were noted when sera negative to crithidia but positive on metaphase substrate were reacted similarly. Also, the staining pattern of positive sera were similar to that of the DNA stain Hoechst 33258 again suggesting DNA binding by positive sera. ${ }^{5}$

Only $4.6 \%$ of ANA-positive sera react on metaphase substrate ${ }^{5}$ demonstrating the lack of broad reactivity. Thirty of ninety-two SLE sera ${ }^{4}$ have been shown to be positive in the metaphase test, a finding consistent with the detection of DNA antibodies. Additionally, sera from rheumatoid arthritis patients with a relatively high incidence of antibodies to other nuclear constituents ${ }^{4}$ were negative on metaphase substrate.

It has been suggested ${ }^{10}$ that radioimmunoassay techniques detect IgG antibodies to dsDNA while haemagglutination tests only reveal IgM. Fluorescent tests probably detect both classes of antibody and in addition can be used to determine whether the putative antibodies bind complement components in vitro. ${ }^{12} 13$ We have previously found that of 23 sera positive to $\mathrm{CL}$ kinetoplast immunofluorescence only 11 showed greater than $30 \%$ binding on Farr assay. ${ }^{4}$ This phenomenon may explain the lesser degree of association between the less sensitive Farr assay and either of the immunofluorescence tests, than between the two immunofluorescence tests.

Crowe and colleagues ${ }^{14}$ have compared the $\mathrm{CL}$, Farr, haemagglutination and millipore assays for dsDNA antibodies. They reported highly significant correlation between the $\mathrm{CL}$ technique, millipore filter method and Farr technique, with highest degree of association occurring between millipore method and Farr assay. They also found, as we have, that the haemagglutination method did not correlate well with any of the other tests.

A correlation coefficient of 0.74 has been previously reported between $C L$ immunofluorescence and endonuclease-treated DNA filter assay in patients with dsDNA antibodies. ${ }^{8}$ The number of positive sera assessed was 48. Our prospective analysis of 691 sera revealed 114 to be positive to either or both metaphase and Farr assays and yielded a correlation coefficient of $0 \cdot 84$.

Our experiments clearly demonstrate that immunofluorescence tests using human metaphase chromosomes correlate extremely well with results of other, more established, tests for dsDNA antibodies. This observation, together with the relative simplicity, reliability and increased sensitivity of the metaphase assay, provide very compelling reasons for the adoption of this method as a routine laboratory test for dsDNA antibodies.

The authors are grateful to Associate Professor JD Wilson for support and criticism, Norma Turner and Anne Jenkin for manuscript typing, immunology staff for performing the assays, Sharon Hobbs for 
statistical consultation and Malcolm Parslow and Diana Chambers for metaphase substrate.

\section{References}

1 Whaley K, Hughes GRV, Webb OO. Systemic lupus erythematosus in man and animals. In: Watson Buchanan W, Carson DW, eds. Recent advances in rheumatology No 1. Edinburgh: Churchill Livingstone, 1976:74.

2 Lachman PS, Petrie E. Analysis of results of the workshop study on measurement of anti-DNA antibodies. Ann Rheum Dis 1977; 36, suppl: 76.

${ }^{3}$ Aarden LA, DeGroot ER, Feltkamp TEW. Immunology of DNA III. Crithidia luciliae a simple substrate for the determination of anti-dsDNA with the immunofluorescence technique. Ann NY Acad Sci 1975;245:505-15.

- Somerfield SD, Wilson JD. A new simple technique for the identification of antibodies against double stranded DNA : Preliminary communication. NZ Med J 1979;98:58-9.

- Somerfield SD, Wilson JD. The detection of double stranded DNA antibody using human metaphase chromosomes. J Clin Lab Immunol 1980;3:203-7.

- Hungerford DA. Leucocytes cultured from small inocula of whole blood and the preparation of metaphase chromosomes by treatment with hypotonic $\mathrm{KCl}$. Stain Technol 1965;40:333.

7 Davis P, Christian B, Russell AS. Immunofluorescent technique of antibodies to n-DNA: comparison with radioimmunoassay. $J$ Rheumatol 1977;4:15-20.

${ }^{8}$ Chubick A, Sontheimer RD, Gilliam JN, Ziff M. An appraisal of tests for native DNA antibodies in connective tissue diseases. Clinical usefulness of Crithidia luciliae assay. Ann Intern Med 1978;89:186-92.

- Ballou SP, Kushner I. Antinative DNA detection by the Crithidia luciliae method. Arthritis Rheum 1979;22:321-7.

${ }^{10}$ Slater NGP, Cameron JS, Lessof MH. The Crithidia luciliae kinetoplast immunofluorescence test in systemic lupus erythematosus. Clin Exp Immunol 1976;25:480-6.

11 Freund JE. Mathematical statistics. 2nd ed. London: Prentice Hall, 1972:378-81.

12 Aarden LA, Lakmaker F, DeGroot ER. Effect of monogamous bivalent binding on the detection and pathogenicity of antibodies to DNA. San Francisco, California, USA: XIV International Congress of Rheumatology June 26-July 1, 1977.

13 Beaulieu A, Quismorio FP, Friou GJ. Antibodies to double stranded DNA (dsDNA) and their capacity to fix complement; relation to disease activity and renal involvement. San Francisco, California, USA: XIV International Congress of Rheumatology June 26July 1, 1977.

${ }^{14}$ Crowe W, Kushner I, Clough JD, Vignor PJ. Evaluation of the Crithidia luciliae method for detection of antibodies to dsDNA: comparison with millipore filter, Farr and haemagglutination tests. San Francisco, California, USA: XIV International Congress of Rheumatology June 26July 1, 1977.

Requests for reprints to: Dr SD Somerfield, Department of Immunology, Auckland Hospital, Park Road, Auckland, New Zealand. 